RU Организация самостоятельной работы студентов по рисунку

\title{
в высшей школе
}

\author{
Бостанов М. С., Дерева Р. М.
}

\begin{abstract}
Аннотация. Цель исследования - обосновать возможность формирования навыков самообразования у студентов на основе индивидуализации обучения посредством организации самостоятельной работы по рисунку. Анализ научно-методических источников психологов, педагогов, художниковпедагогов прошлого и настоящего позволил в статье актуализировать проблему организации самостоятельной работы студентов по рисунку на современном этапе развития образования. Обозначены роль рисунка в профессиональном образовании художника, художника-педагога, дизайнера и значимость самостоятельной работы по этому предмету при обусловленной необходимости в ежедневных упражнениях для освоения изобразительной грамоты. Рассмотрены мотивирующие факторы для самообразования, саморазвития, в том числе способы стимулирования и сопровождения педагогом самостоятельной работы обучающихся. Научная новизна исследования - обоснование методических рекомендаций по организации самостоятельной работы студентов по рисунку в соответствии с современной парадигмой требований к специалистам, в значительной мере заключающихся в умении ими самостоятельно получать знания - способности к саморазвитию (в научном и творческом планах), самообразованию, инновационным поискам. В результате на основе анализа учебно-методических источников и собственного опыта сформулированы методические рекомендации для сопровождения самостоятельной формы обучения студентов по рисунку.
\end{abstract}

\section{EN Organizing Individual Work of Students on Drawing in Higher School}

\author{
Bostanov M. S., Dereva R. M.
}

\begin{abstract}
The paper aims to give reasons for the possibility of development of students' self-education skills based on the individualization of learning through the organization of individual work on drawing. The analysis of the scientific and methodological works of psychologists, pedagogists, teaching artists of the past and the present has allowed actualizing in the article the problem of the organization of students' individual work on drawing at the current stage of education development. The role of drawing in the professional education of an artist, teaching artist, designer and the importance of individual work on this subject in the condition of the need for daily exercises for mastering the visual art literacy have been identified. Motivating factors for self-education, self-development, including the teachers' ways to stimulate and support students' individual work, have been considered. The scientific originality of the research lies in the fact that it supports the methodological recommendations for the organization of students' individual work on drawing in accordance with the modern paradigm of requirements for the specialists which mainly consist in their ability to gain knowledge independently - in the skills of self-development (in the scientific and creative ways), self-education, search for innovations. As a result of the analysis of teaching materials and personal experience, methodological guidelines for the support of teaching drawing to students through the individual form of work have been formulated.
\end{abstract}

\section{Введение}

Актуальность темы исследования обусловлена тем, что в современной системе высшего образования происходит поиск путей интеграции старых сложившихся традиций в обучении с новыми тенденциями в этой сфере, связанными с глобальным социокультурным преобразованием общества на фоне развивающихся информационно-коммуникативных технологий, влияющих на мировоззрение и мироощущение человека, а также с приобщением России к мировому образовательному пространству.

Научная статья (original research article) | https://doi.org/10.30853/ped20210125

(๔ 2021 Авторы. ООО Издательство «Грамота» (๔ 2021 The Authors. GRAMOTA Publishers). Открытый доступ предоставляется на условиях лицензии СС ВY 4.0 (open access article under the CС BY 4.0 license): https://creativecommons.org/licenses/by/4.0/ 
Рисунок является основой основ всех видов изобразительного искусства. Обучающемуся рисунку необходимо хорошо овладеть им. Педагоги, понимая особую важность этой дисциплины, при планировании своих учебных программ по рисунку строго контролируют соблюдения принципов и методов обучения (Цит. по: Ростовцев, 1983, с. 3). Программа учебного предмета «Рисунок» составляется с учетом выработанных традиций реалистической школы обучения изобразительной грамоте. В них на современном этапе большое место отводится самостоятельной работе. Самостоятельная работа студентов всегда рассматривалась как неотъемлемая составляющая результата профессионального образования. Учитывая значимость рисунка в художественном образовании, необходимость в дистанционном обучении студентов (для некоторой категории студентов) и в ежедневных упражнениях для приобретения практических умений и навыков в рисунке делает рассматриваемую тему статьи актуальной.

Задачи исследования:

- обосновать значимость самостоятельной работы как важнейшей составляющей организации учебного процесса по изобразительному искусству в вузе;

- обозначить мотивирующие факторы для обучения студентов рисунку при организации и сопровождении самостоятельной работы;

- сформулировать методические рекомендации для самостоятельной работы студентов по рисунку.

Теоретической базой исследования являются разработанные в научной литературе теоретические и организационно-деятельностные проблемы обучения и воспитания обучающихся. Психологией исследования творчества и его значении в педагогике занимался Я. А. Пономарев (1976); теория обучения и воспитания освещены в педагогике В. А. Сластенина, И. Ф. Исаева, Е. Н. Шиянова (2008); вопрос организации самостоятельной работы студентов рассматривается в исследованиях И. П. Ковалевского (2000), Е. В. Щербаковой (2010), И. И. Ушатиковой, К. С. Ушатиковой (2017); к вопросу творчества и обучения изобразительной грамоте на основе компетентностного подхода обращена монография И. Н. Полынской (2012); процессу самообучения, личностного и профессионального развития уделено внимание в пособии Н. С. Ефимовой, Н. В. Плаксиной, Е. С. Ефимовой (2018); значимость рисунка в обучении основам изобразительной грамоты обосновывается в трудах Н. Н. Ростовцева (1983), Г. В. Беды (1989), И. Б. Шешко (1981), А. О. Барща (1970); формированию профессиональных компетенций студентов на основе организации самостоятельной работы посвящена монография И. В. Георге (2016); методические рекомендации по организации самостоятельной работы составлены Ж. В. Пономаревым (Самостоятельная работа..., 2017); организация самостоятельной работы обучающихся в профессиональных образовательных учреждениях исследована В. И. Сахаровой, Н. О. Хлупиной (2016); познавательная самостоятельность студентов в условиях дистанционного обучения рассмотрена И. Н. Артамоновой (2020); способы мотивации учебной деятельности студентов вуза предложены М. Н. Крыловой (2013).

Методы исследования:

1) теоретические методы: изучение и анализ научно-методической, психолого-педагогической и специальной литературы по проблеме исследования; анализ учебных пособий и методических материалов по рисунку и самостоятельной работе студентов;

2) эмпирические методы: наблюдение за деятельностью студентов на аудиторных и внеаудиторных занятиях.

Базой исследования является Карачаево-Черкесский государственный университет им. У. Д. Алиева, Художественно-графический факультет. При поступлении в вуз предполагается подготовленность абитуриента по выбранной профессии, но опыт нашего университета показывает, что более $40 \%$ вновь поступивших на Художественно-графический факультет не обладают достаточными навыками в рисовании. При незначительном количестве часов, отводимых на данном этапе на практические занятия, эти студенты должны получить достаточно основательные знания и умения по рисунку.

Практическая значимость исследования заключается в возможности использования полученных результатов (способ выявления характерных особенностей, потенциальных возможностей студентов и мотивирования их на активную работу, индивидуализацию обучения и т.д.) в практике педагога высшего учебного заведения.

\section{Значимость самостоятельной работы как важнейшей составляющей организации учебного процесса по изобразительному искусству в вузе}

Н. С. Ефимова, Н. В. Плаксина, Е. С. Ефимова (2018) обозначили роль самостоятельной работы студентов (СРС): «СРС предназначена не только для овладения каждой дисциплиной, но и для формирования навыков самостоятельной работы вообще, в учебной, научной, профессиональной деятельности, способности принимать на себя ответственность самостоятельно решить проблему, находить конструктивные решения. Необходимо исходить из требований к уровню самостоятельности выпускников, чтобы этот уровень был достигнут за годы обучения» (с. 108).

В процессе подготовки будущего художника-педагога, дизайнера решается множество связанных между собой задач, в результате чего формируется мировоззрение и художественный вкус, усваиваются необходимые научные знания и приобретаются специальные практические умения и навыки, развиваются потенциальные творческие способности (Полынская, 2012, с. 3). К важной задаче профессионального образования относится подготовка специалиста, способного к саморазвитию, самообразованию. Массовый переход (по объективной 
причине) к самостоятельной работе обучающихся предполагает ее планирование в соответствии с современными реалиями развития общества и образования в нашей стране, активизацию перехода в соответствии с потребностью и возможностью личности (индивидуализированность).

Преподаватели вуза при планировании самостоятельной работы учитывают важность дисциплины (рисунок), требующей пристального внимания особенно на первоначальном этапе обучения изобразительной грамоте, так как рисунок является основой профессионального обучения. Об этом говорится во всех теоретических трудах художников-педагогов прошлого, например, Д. Н. Кардовский писал: «Так как рисунок есть построение графическим путем формы на плоскости, то поэтому прежде всего необходимо овладеть рисунком, чтобы в дальнейшем на его основе и в связи с формой строить живопись» (Цит. по: Рисунок, живопись, композиция, 1989, с. 49).

Значимость самостоятельной работы по рисунку определяется и тем, что для овладения основами изобразительной грамоты необходима ежедневная работа. Обучение построено на длительном многочасовом рисовании с натуры при соблюдении принципа систематичности и последовательности, так как каждое предыдущее задание учебного рисунка является частью последующего. Одновременно с этим идет работа над кратковременными рисунками и зарисовками, являющимися неотъемлемой частью обучения.

Систематическое выполнение набросков и зарисовок развивает способности рисовальщика, формируя нужные ему для изобразительной деятельности качества: способность к целостному восприятию и творческому отношению к рисованию с натуры; помогает овладению техническими навыками и вырабатывает индивидуальный графический язык; развивает остроту видения, наблюдательность и образное мышление; формирует умение передавать типические черты окружающей действительности и способствует накоплению знаний о формообразовании предметов. Для выполнения набросков необходимо овладеть методом анализа и обобщения, умением выявлять в предметах и явлениях типическое и характерное.

Таким образом, ежедневное выполнение рисунков, в том числе и при самостоятельной аудиторной и внеаудиторной работе, является обязательным. Н. Н. Ростовцев говорит о том, что художник, даже достигнув определенного профессионального мастерства, без тренировки (постоянных упражнений) утрачивает свободу и виртуозность владения языком изобразительного искусства. Большое значение ежедневной работе придавал английский художник-теоретик XVIII века Д. Рейнольдс: «Овладение рисунком, подобно игре на музыкальном инструменте, может быть достигнуто лишь бесчисленными упражнениями, мне нечего поэтому повторять... что карандаш должен быть всегда в ваших руках» (Цит. по: Ростовцев, 1983, с. 54).

Следовательно, основная нагрузка профессиональной подготовки художника-педагога, дизайнера ложится на самостоятельную работу, которая разделяется на такие виды, как: аудиторные занятия-консультации с преподавателем; аудиторные занятия (индивидуальные, коллективные) без непосредственного присутствия преподавателя (в том числе и дистанционная форма обучения); внеаудиторные занятия (домашняя работа). Последние два вида занятий должны сопровождаться частичным контролем со стороны преподавателя, так как самостоятельная работа не означает полное дистанцирование педагога. Особенно это касается обучения рисунку.

\section{Мотивирующие факторы для обучения студентов рисунку при организации и сопровождении самостоятельной работы}

Студент должен понимать, что процесс рисования является творческим и познавательным, включающим в себя как изучение строения формы и усвоение правил построения изображения, так и передачу эмоционально-образного восприятия предметов и явлений окружающей нас действительности в их целостности и взаимодействии (Дерева, 2015). Для освоения изобразительной грамоты необходима устойчивая мотивация, зависящая от профессиональной установки педагога и являющаяся особенно актуальной в настоящее время при пассивности некоторой части молодежи, в том числе среди студентов нашего вуза. В значительной степени причиной этому является отсутствие регулярности и целенаправленности студентов в обучении. В связи с этим мотивы являются движущими силами процесса обучения и усвоения материала (Мормужева, 2013).

Мотивированность означает осознание студентом целей, задач и ожидаемого итога обучения. Он должен быть активным в учебном процессе на фоне потребности в обучении и осознания необходимости в развитии профессиональных качеств. Большое значение имеет воздействие педагога на студента, пробуждающее его мотивацию (Сахарова, Хлупина, 2016).

При разнородности подготовки студентов по дисциплине для их мотивации преподавателю необходимы особые усилия, содействующие оптимизации учебного процесса:

1. Убеждение в важности рисунка как основы обучения изобразительному искусству. При этом необходим индивидуальный подход к каждому студенту.

2. Обоснование значимости каждой темы программы обучения по рисунку, составленной по принципу «от простого к сложному». Без прохождения очередной темы (особенно на начальной стадии обучения) невозможно успешное освоение учебной программы (каждая предыдущая тема является частью последующих), то есть ранее усвоенные знания и навыки являются основой для решения новых положений и задач рисунка.

3. Самым сильным мотивирующим фактором может стать убеждение в важности рисунка в дальнейшей эффективной профессиональной деятельности.

4. Особая роль для мотивированности студента отводится убеждению в значимости самостоятельной работы, заключающейся в ежедневном выполнении определенных упражнений. В основном самостоятельная 
работа является закреплением знаний и умений, полученных на аудиторных занятиях (с преподавателем), но студент может работать и над собственными заданиями.

5. Эффективным мотивирующим фактором является словесное поощрение педагогом действительных положительных результатов в работе студента и собственное осознание студентом этих результатов (самооценка) при активной работе над рисунком (Сахарова, Хлупина, 2016).

6. В виде поощрения студентов за хорошую работу (самостоятельную) в балльно-рейтинговой системе существует графа «активность студента». Также в качестве стимула для активизации учебной деятельности служат выставки лучших учебных работ по рисунку.

В первом пункте перечисленных мотиваций студентов обозначена необходимость индивидуального подхода, предполагающая изучение педагогом таких личностных качеств студента, как:

- ответственное отношение к учебе с пониманием ее важности в развитии профессиональных качеств;

- осознание студентом роли самостоятельной работы по рисунку и готовность к ней;

- наличие у студента способности к приложению волевых усилий для получения знаний и выполнения ежедневных практических работ по рисунку;

- уверенность в себе и способность к саморазвитию, самообразованию, регулированию самостоятельной работы в соответствии с необходимыми для профессиональной подготовки действиями.

По поводу личностных качеств обучающегося в своем исследовании И. В. Георге (2016) отмечает: «Кроме необходимых знаний, умений, опыта деятельности, фактором формирования и развития профессиональных компетенций является личностный потенциал субъекта (студента), включающий мотивацию, целеполагание, саморегуляцию, рефлексию и другие механизмы саморазвития» (с. 82).

Следовательно, учет индивидуальных особенностей студента необходим при организации учебного процесса по рисунку для сопровождения и руководства, в том числе и самостоятельной работой. Сопровождение и руководство необходимы для повышения уровня самостоятельной работы (Сахарова, Хлупина, 2016, с. 376).

Контроль преподавателя предполагает консультирование студента в определенное время, одновременно продолжается организация учебно-воспитательной работы, заранее подготавливаются новые задания по программе для самостоятельной работы. При развитии в наше время информационно-коммуникативных технологий такая работа может проводиться дистанционно в интерактивном режиме.

Таким образом, определены мотивирующие факторы, а именно: важность рисунка как основы изобразительного искусства и в будущей успешной профессиональной деятельности; значимость самостоятельной работы (ежедневные упражнения по рисунку); словесное поощрение педагогом положительных результатов в работе студента с соответствующей отметкой в балльно-рейтинговой системе аттестации, способные активировать студентов к учебе, самообразованию, являющиеся главной движущей силой в поведении и деятельности человека, в том числе и в процессе формирования профессиональных качеств будущего специалиста. Также обозначена роль педагога в повышении мотивации студента к саморазвитию, заключающаяся в индивидуализации обучения.

\section{Методические рекомендации для активизации самостоятельной работы студентов по рисунку}

Схема необходимых действий для сопровождения самостоятельной работы студентов по рисунку выглядит следующим образом (Рисунок 1).

\begin{tabular}{|c|c|c|c|c|}
\hline & & \multicolumn{2}{|c|}{$\begin{array}{c}\text { Самостоятельная работа по рисунку. } \\
\text { Методические рекомендации }\end{array}$} & \\
\hline \multicolumn{2}{|c|}{$\begin{array}{l}\text { Исследование эмпирическим } \\
\text { методом степени } \\
\text { подготовленности и } \\
\text { возможностей студента по } \\
\text { рисунку }\end{array}$} & $\begin{array}{l}\text { Выявление ошибок в рисунке, } \\
\text { допускаемых студентом }\end{array}$ & $\begin{array}{l}\text { Подбс } \\
\text { пособ } \\
\text { выявл } \\
\text { допус } \\
\text { неточ } \\
\text { студе }\end{array}$ & \\
\hline \multicolumn{2}{|c|}{$\begin{array}{l}\text { Определение дополнительных } \\
\text { заданий для развития } \\
\text { индивидуальных способностей } \\
\text { наряду с программными }\end{array}$} & $\begin{array}{l}\text { Налаживание способов общения и } \\
\text { сопровождения самостоятельной } \\
\text { работы студентов в каждой } \\
\text { конкретной ситуации - } \\
\text { непосредственное взаимодействие } \\
\text { со студентом, интерактивное } \\
\text { сетевое дистанционное } \\
\text { взаимодействие }\end{array}$ & \multicolumn{2}{|c|}{$\begin{array}{l}\text { Консультирование с } \\
\text { обращением внимания } \\
\text { студента на } \\
\text { допущенные им } \\
\text { неточности. } \\
\text { Промежуточный } \\
\text { просмотр рисунков ๔ }\end{array}$} \\
\hline & \multicolumn{3}{|c|}{$\begin{array}{l}\text { Аттестация студентов с рекомендацией лучших работ на } \\
\text { выставку }\end{array}$} & \\
\hline
\end{tabular}

Рисунок 1. Самостоятельная работа студентов по рисунку. Методические рекомендации 
Элемент 1. Исследование эмпирическим методом степени подготовленности и возможностей студента по рисунку.

Выявление индивидуальных возможностей студента по рисунку путем наблюдения и беседы:

- теоретические знания законов реалистического изображения трехмерного объекта на двухмерной плоскости (беседа, наблюдение) - перспектива, композиция, принципы формообразования объектов предметно-пространственной среды, человека, животных и т.д.;

- практические умения и навыки по рисунку (наблюдение) - правильное размещение изображения на плоскости, ведение рисунка «от общего к частному», умение детализировать на основе знаний строения формы, определение главного и второстепенного в объекте изображения и способность их выявления на рисунке, владение изобразительными средствами рисунка (линия, штрих и т.д.), выразительное отображение художественного образа.

На этом этапе исследования можно обнаружить не только профессиональные знания и умения, но и личностные качества студента - уверенное изображение и владение инструментарием говорит о том, насколько часто он упражняется в рисовании, о его увлеченности изобразительной деятельностью и готовности к саморазвитию. Даже при наличии природного дара практические навыки приходится развивать для профессиональной практической работы.

Элемент 2. Выявление ошибок в рисунке, допускаемых студентом.

Наблюдения за практической работой по рисунку, проводимые на 1 курсах (отделений ИзО и дизайна), дали возможность проанализировать выявленные частые ошибки в изображениях различных постановок при решении учебных задач.

1. Ошибки и погрешности в рисунке, присущие многим студентам (45\%).

2. Ошибки и погрешности в рисунке, присущие отдельным студентам (5\%).

Удовлетворительно с заданиями справляются 50\% студентов.

Основные неточности, допускаемые в рисунке, касаются следующих аспектов: погрешности в композиционном размещении изображения на формате листа, неумение последовательно работать «от обобщенной формы к детализации с последующим обобщением», неспособность методом визирования определить пропорции объекта, несоблюдение законов линейной перспективы при построении и световоздушной перспективы при «лепке» формы.

В дальнейшем, при переходе к более сложным формам изображения (например, рисунок головы человека), студенты, которые не имели опыта работы над рисунком, также затрудняются при работе над постановкой.

Элемент 3. Подбор наглядных пособий с учетом выявленных часто допускаемых неточностей в рисунках студента.

Наглядные пособия могут быть различного характера в зависимости от допускаемых студентами ошибок схематические рисунки с демонстрацией линейного построения геометрических тел (с одной точкой и двумя точками схода на линии горизонта - куб, четырех- и шестигранная призма и т.д.), предметов быта, схематические рисунки головы с принципами построения (с учетом законов перспективы) с различных точек зрения и т.д. В качестве наглядности необходимо использовать рисунки старых мастеров с обращением внимания студента на решение художниками задач, с которыми обучающийся не всегда справляется. Полезными пособиями являются учебные рисунки студентов предыдущих лет. Важная роль в качестве наглядности принадлежит учебникам по рисунку, так как в них имеются схемы, репродукции работ старых мастеров, современных художников и теоретическое обоснование принципов изображения конкретной постановки. Основными источниками теоретического и практического обучения рисунку являются: Г. В. Беда. Основы изобразительной грамоты, 1981; И. Б. Шешко. Построение и перспектива рисунка, 1981; Н. Н. Ростовцев. Академический рисунок, 1984; А. С. Пучков, А. В. Триселев. Методика работы над натюрмортом, 1982; А. О. Барщ. Наброски и зарисовки, 1970; Р. М. Дерева. Рисунок. Основы изобразительной грамоты, 2015; Н. Г. Ли. Рисунок. Основы учебного академического рисунка, 2005 и другие.

Элемент 4. Определение дополнительных заданий для развития индивидуальных способностей студентов по рисунку наряду с программными.

Как правило, учебные программы по рисунку составляются преподавателем традиционно согласно последовательности обучения «от простого к сложному» без учета индивидуальных особенностей обучающихся, так как предполагается, что поступающие в вуз студенты должны иметь хорошую подготовку по специальности. Но опыт работы с контингентом 1 курса показывает разнообразие в подготовленности студентов по рисунку - часть студентов имеют очень хорошую подготовку, часть - среднюю и часть - слабо подготовлены.

Дополнительные задания по рисунку для развития индивидуальных способностей необходимо составлять с учетом и хорошо подготовленных студентов, и слабо подготовленных. Сильные в профессиональном отношении обучающиеся должны развиваться дальше, и для них могут быть усложнены задания, например, даны задания (наряду с программными), носящие более творческий характер, чем учебные - это выполнение рисунков с использованием различных средств выразительности (мягкие материалы) и технических приемов. Например, углем можно выполнить очень выразительный рисунок, в том числе и геометрических тел.

Для слабо подготовленных студентов дополнительным заданием является выполнение упражнений, способствующих развитию моторики руки, например, изображение поисковых линий в разных направлениях, штрихов разной тональности согласно шкале от светлого к темному и т.д. 
Элемент 5. Налаживание способов общения и сопровождения самостоятельной работы студентов в каждой конкретной ситуации - непосредственное общение со студентом, интерактивное сетевое дистанционное взаимодействие.

Контакт «преподаватель-студент» для руководства самостоятельной работой и её сопровождения может проходить при непосредственной запланированной встрече в аудитории, где студентом демонстрируется усвоение теоретического материала и умение применять эти знания на практике, то есть в рисунках. По итогам проверки самостоятельных работ руководителем отмечаются отрицательные и положительные моменты в рисунках, а также даются задания с учетом устранения ошибок и дальнейшего развития навыков обучающегося.

Существенно облегчила общение руководителя со студентом сетевая система. Интерактивная модульная связь предоставила широкую возможность не только предоставления теоретического материала по обучаемым дисциплинам, но и разнообразных наглядных виртуальных пособий - схем, рисунков, видеоматериалов с демонстрацией последовательного изображения постановки, а также проведения мастер-класса преподавателем (с учетом индивидуальных особенностей студентов) и т.д.

Интерактивная дистанционная связь существует давно, но особенно популярной стала во время перехода образовательной системы на дистанционное обучение (во время изоляции). Эта связь стала полезной для обучения студентов, находящихся по разным причинам на индивидуальном обучении.

Элемент 6. Консультирование с обращением внимания студента на допущенные им неточности. Промежуточный просмотр рисунков.

Коллективный просмотр самостоятельных работ дает высокий результат для профессионального роста обучающегося, у которого на этом этапе есть возможность в плане восприятия своих работ в сравнении с рисунками других студентов. Некоторые недочеты видны самому обучающемуся, но руководитель должен удостовериться в правильности оценки студентом своих работ и провести консультацию, сравнивая результаты решения отдельных задач другими участниками просмотра.

Элемент 7. Аттестация студентов с рекомендацией лучших работ на выставку.

Итоговая аттестация проводится коллективно в присутствии преподавателей кафедры изобразительного искусства, на которой ведущим данного курса преподавателем по рисунку предлагается оценка работ каждого обучающегося, указывается его профессиональный рост, характеризуется степень самостоятельности в решении учебных задач, активность студента в плане самообразования. Рядом с оценкой (в черновике) преподаватель отмечает достоинства и недостатки в работах каждого обучающегося для оглашения и обсуждения в присутствии студентов результатов просмотра. Лучшие работы рекомендуются для участия в итоговой выставке учебных работ.

Таким образом, при использовании предложенной схемы организации самостоятельной работы по рисунку, заключающейся в исследовании подготовленности студентов по дисциплине, выявлении ошибок в работах, допускаемых ими, определении дополнительных заданий для развития индивидуальных способностей наряду с программными были проведены аттестации (просмотры продуктов творческой деятельности обучающихся). Вследствие этого обнаружилась тенденция к качественному росту профессиональных способностей студентов: в начале первого семестра обучения в ходе просмотров - на 35,3\%: промежуточные аттестации, проводимые в середине семестра, показали увеличение до 48,7\%, итоговая аттестация - 87,2\%. Процентные отношения выведены на основе оценок в ходе аттестаций.

\section{Заключение}

Таким образом, авторы пришли к следующим выводам:

1. Самостоятельная работа студентов над рисунком является важнейшей составляющей организации учебного процесса в вузе на современном этапе. Самостоятельное овладение учебным материалом является неотъемлемой частью обучения рисунку как синтетической формы образования, базирующейся на использовании широкого спектра технических средств, а также традиционных и инновационных технологий. Без повышения роли самостоятельной работы в образовательном процессе подготовка квалифицированных специалистов, конкурентоспособных на рынке труда, невозможна.

2. Мотивирующие факторы для обучения студентов рисунку при организации и сопровождении самостоятельной работы (значимость самостоятельной работы по рисунку для приобретения профессиональных навыков, поощрение и представление лучших рисунков на выставке учебных работ) позволяют активизировать обучающихся к учебной деятельности.

3. Сформулированные методические рекомендации для самостоятельной работы студентов по рисунку, которые основаны на индивидуальном подходе к обучающимся, позволяют повысить мотивацию и эффективно развивать профессиональные способности студентов.

Перспективы дальнейшего исследования связаны с созданием технологии формирования компетенций обучающихся по отдельным темам учебной программы при организации самостоятельной работы по рисунку.

\section{Источники | References}

1. Артамонова И. Н. Развитие познавательной самостоятельности студентов как обязательное условие дистанционного обучения // Организация самостоятельной работы студентов по иностранным языкам. 2020 . № 3.

2. Барщ А. О. Наброски и зарисовки. М.: Искусство, 1970. 
3. Беда Г. В. Основы изобразительной грамоты. М.: Просвещение, 1989.

4. Георге И. В. Формирование профессиональных компетенций студентов образовательных организаций высшего образования на основе организации самостоятельной работы: монография. Тюмень: ТИУ, 2016.

5. Дерева Р. М. Рисунок. Основы изобразительной грамоты: учебное пособие. Карачаевск: КЧГУ, 2015.

6. Ефимова Н. С., Плаксина Н. В., Ефимова Е. С. Психология и педагогика высшей школы: учебное пособие. М.: РХТУ им. Д. И. Менделеева, 2018.

7. Ковалевский И. П. Организация самостоятельной работы студента // Высшее образование в России. 2000 . № 1.

8. Крылова М. Н. Способы мотивации учебной деятельности студентов вуза // Перспективы науки и образования. 2013. № 3.

9. Мормужева Н. В. Мотивация обучения студентов профессиональных учреждений. 2013. URL: https://moluch. $\mathrm{ru} / \mathrm{conf} / \mathrm{ped} /$ archive/98/4633/

10. Полынская И. Н. Формирование профессиональной компетенции в области рисунка у студентов факультета искусств и дизайна: монография. Нижневартовск: Изд-во Нижневарт. гуманит. ун-та, 2012.

11. Пономарев Я. А. Психология творчества. М.: Наука, 1976.

12. Рисунок, живопись, композиция / сост. Н. Н. Ростовцев, С. Е. Игнатьев, Е. В. Шорохов. М.: Просвещение, 1989.

13. Ростовцев Н. Н. Очерки по истории методов преподавания рисунка. М.: Изобразительное искусство, 1983.

14. Самостоятельная работа студента в рамках курса академического рисунка: методические указания / сост. Ж. В. Пономарёва. Челябинск: Издательский центр ЮУрГУ, 2017.

15. Сахарова В. И., Хлупина Н. О. Организация самостоятельной работы обучающихся в профессиональных образовательных учреждениях: метод. Рекомендации. Кемерово: КРИРПО, 2016.

16. Сластенин В. А., Исаев И. Ф., Шиянов Е. Н. Педагогика: учебник для вузов. Изд-е 9-е / под ред. В. А. Сластенина. М.: Академия, 2008.

17. Ушатикова И. И., Ушатикова К. С. Внеаудиторная самостоятельная работа как средство самореализации студента вуза // Педагогика. Вопросы теории и практики. 2017. № 4.

18. Шешко И. Б. Построение и перспектива рисунка. Минск: Высшая школа, 1981.

19. Щербакова Е. В. Самостоятельная работа студентов как важнейшая составляющая организации учебного процесса в вузе // Молодой ученый. 2010. Т. 2.

\section{Информация об авторах | Author information}

RU Бостанов Магомет Сосуранович ${ }^{1}$, доц.

Дерева Райа Мажитовна ${ }^{2}$, к. иск., доц.

1,2 Карачаево-Черкесский государственный университет имени У. Д. Алиева, г. Карачаевск

EN Bostanov Magomet Sosuranovich

Dereva Raia Mazhitovna ${ }^{2}, \mathrm{PhD}$

${ }^{1,2}$ Karachay-Circassian State University named after U. D. Aliev, Karachaevsk

22dereva2020@mail.ru

\section{Информация о статье | About this article}

Дата поступления рукописи (received): 15.10.2021; опубликовано (published): 28.12.2021.

Ключевые слова (keywords): самостоятельная работа; рисунок; высшая школа; индивидуализации обучения; художник; individual work; drawing; higher school; individualizations of learning; artist. 